Brazilian Journal
of Chemical
Engineering

ISSN 0104-6632

Printed in Brazil

www.abeq.org.br/bjche

Vol. 25, No. 03, pp. 543 - 552, July - September, 2008

\title{
EXTRACTION OF CAFFEINE, CHLOROGENIC ACIDS AND LIPIDS FROM GREEN COFFEE BEANS USING SUPERCRITICAL CARBON DIOXIDE AND CO-SOLVENTS
}

\author{
A. B. A. de Azevedo ${ }^{1}$, Paulo Mazzafera ${ }^{2 *}$, R. S. Mohamed $^{1 \dagger}$, \\ S. A. B. Vieira de Melo ${ }^{3}$ and T. G. Kieckbusch ${ }^{1}$ \\ ${ }^{1}$ Faculdade de Engenharia Química, Universidade Estadual de Campinas, \\ C.P. 6066, 13083-970, Campinas - SP, Brasil. \\ ${ }^{2}$ Instituto de Biologia, Universidade Estadual de Campinas, Campinas - SP, Brasil. \\ E-mail:pmazza@unicamp.br \\ ${ }^{3}$ Departamento de Engenharia Química, Escola Politécnica, \\ Universidade Federal da Bahia, 40210-630, Salvador - BA, Brasil.
}

(Received: October 10, 2007 ; Accepted: December 10, 2007)

\begin{abstract}
The paper reports on experimental data on the extraction of caffeine, coffee oil and chlorogenic acids from green coffee beans using pure supercritical $\mathrm{CO}_{2}$ and supercritical $\mathrm{CO}_{2}$ modified with ethanol $(5 \%$ $\mathrm{w} / \mathrm{w})$ and isopropyl alcohol $(5 \% \mathrm{w} / \mathrm{w})$ at 50 and $60^{\circ} \mathrm{C}$ and 15.224 .8 e $35.2 \mathrm{MPa}$. In this study extraction kinetics were obtained for all assays i.e. samples were collected at several time intervals for each solvent and mixed solvent. When pure $\mathrm{CO}_{2}$ and $\mathrm{CO}_{2}$-ethanol mixed solvent were used, an increase in pressure resulted in an increase in the amount of oil extracted. When $\mathrm{CO}_{2}$ was modified with isopropyl alcohol, the amount of coffee oil extracted also increased with pressure. Caffeine extraction initially increased and subsequently decreased with pressure. Chlorogenic acids were only extracted when isopropyl alcohol was used as a cosolvent. An increase in extraction temperature resulted in a decrease of caffeine and oil extraction (retrograde condensation) when only $\mathrm{CO}_{2}$ was used as solvent. With the use of co-solvent this retrograde behavior was no longer observed and the increase in temperature resulted in the increase in the extracted amounts of caffeine, coffee oil and chlorogenic acids.
\end{abstract}

Keywords: Supercritical extraction; Coffee; Coffee oil; Caffeine; Chlorogenic acid; Co-solvent.

\section{INTRODUCTION}

Active principles obtained from natural products are widely used by the pharmaceutical, cosmetic and food industries as raw materials for a large number of industrialized products (Cordel, 2000). Coffee beans are an important source of some active principles. Caffeine, the most widely consumed alkaloid in the world, is found in coffee beans (approximately 1-2 wt.\%), together with others valuable active principles in still higher concentration than caffeine. These active components include coffee oil, which is of special interest to the cosmetic and pharmaceutical industries, and chlorogenic acids to which several therapeutic properties have been attributed and are typically found in concentrations of 7-13 wt.\% and 6-9 wt.\%, respectively (Folstar, 1985, Clifford, 1985; Mazzafera et al. 1998; Lima et al., 2000)

Alkaloids, vegetable oils and chlorogenic acids are commonly extracted by conventional methods using organic solvents (chloroform, dichloromethane, 
etc), which are dangerous to handle and harmful to human health and environment (Mohamed, 1997), and under severe process conditions which could result in product thermal degradation (particularly when steam distillation is involved). Despite the high extraction yield of these conventional processes, the selectivity is often low and the purification of the extracted products is very costly (Reverchon et al., 2000).

Supercritical $\mathrm{CO}_{2}$ extraction is among the new emerging clean and environmental friendly technologies for the processing of food and pharmaceutical products (Subramanian et al., 1997; Perrut, 2000). Alkaloids (Santana et al., 2006) and phenolics (Okuno et al., 2002) have been extracted from plants using supercritical $\mathrm{CO}_{2}$. However, this technique strongly depends on the solubility of lowvolatile substances in supercritical fluids, usually $\mathrm{CO}_{2}$, a non-polar solvent, with low affinity for polar substances. So, the solubility of substances in supercritical $\mathrm{CO}_{2}$ decreases with the increase in the number of polar functional groups (e.g. hydroxyl, carboxyl, amino and nitro). Thus the solubility of chlorogenic acid molecules is expected to be low, particularly as the molecular weight increases (Clifford, 1985; Brunner, 1994; Taylor, 1996).

Small additions of polar co-solvents are usually employed to increase the solubility of polar and high molecular weight substances, despite a possible decrease in selectivity (Brunner, 1994). Two major effects are associated with the addition of a cosolvent: I)- its contribution to the enhancement of physical interactions between solute and solvent molecules which, depending on the nature of the solute, can lead to chemical interactions such as hydrogen bonding, and a consequent increase of the overall solubility (Ting et al., 1993; Brunner, 1994), and II)- the higher critical temperature of the mixed solvent when compared to pure solvent (Kim and Johnston, 1987; Brunner, 1994). In the vicinity of the critical point the isothermal compressibility assumes high values, which leads to the clustering of solvent molecules around the solute molecule and thereby enhancing the solubility (Debenedetti et al., 1989; Brunner, 1994). A good example of the co-solvent effect can be seen in effective extraction of caffeine from coffee beans using moistened green coffee beans and water saturated supercritical $\mathrm{CO}_{2}$ as a solvent (Peker et al., 1992; Lack and Seidlitz, 1993).

However, depending on the compound to be extracted the presence of moisture can have negative influence on the extraction process. Snyder et al. (1984) investigated the effect of moisture content on the extraction of soy oil from seeds using supercritical $\mathrm{CO}_{2}$. The authors reported lower extraction rates for moisture contents higher than 12 wt\%. Eggers (1996) also reported a similar result.

Several studies on the extraction of lipids from oleaginous seeds and alkaloids from natural products with supercritical $\mathrm{CO}_{2}$ and supercritical $\mathrm{CO}_{2}$ modified with aliphatic alcohols as co-solvents can be found in the literature. Azevedo and Mohamed (2001) reported that the addition of ethanol to supercritical $\mathrm{CO}_{2}$ decreased the extraction time and the amount of solvent necessary for the extraction of lipids from cupuaçu. Saldaña et al. (2002a,b) used supercritical $\mathrm{CO}_{2}$ and ethanol as a co-solvent in the extraction of methylxantines from guaraná seeds, mate leaves and cocoa beans.

The main objective of this work is to explore and compare the capacity and selectivity of $\mathrm{CO}_{2}$ and $\mathrm{CO}_{2}$ modified with ethanol or with isopropyl alcohol (both acceptable solvents for cosmetics, pharmaceuticals and food processing) in the extraction of caffeine, chlorogenic acids and coffee oil from green coffee beans.

\section{MATERIALS AND METHODS}

\section{Materials}

Green coffee beans (Coffea arabica variety Mundo Novo) were supplied by the Instituto Agronômico de Campinas (Campinas, Brazil). The beans were frozen using liquid nitrogen and ground in a manual mill to avoid oil losses. Ground beans were immediately classified by particle size using a sieve series, and then stored in sealed plastic bags and kept in a freezer until use. The total oil content in this ground material was obtained by gravimetry after hexane extraction in a Sohxlet apparatus. Before each experiment the ground coffee beans were dried in an oven at $65^{\circ} \mathrm{C}$ during $24 \mathrm{~h}$ to reduce sample moisture. This limit of temperature was adopted to avoid the oxidation of the coffee oil. Carbon dioxide (99.9\%) and carbon dioxide, ethanol or isopropyl alcohol mixtures $(5 \% \mathrm{wt} / \mathrm{wt})$ were purchased from White Martins Co. (Campinas, Brazil). Methanol and ethanol, acetone and acetonitrile in HPLC grade (Merck, Rio de Janeiro, Brazil) were purchased from a local supplier.

\section{Experimental Apparatus}

A semi-continuous flow experimental apparatus (Fig. 1) that allows an independent control of temperature and pressure was used for the extraction experiments. The apparatus was designed and 
assembled by LEPPBIO/FEQ/UNICAMP supercritical fluid process research group for pressures up to $41.3 \mathrm{MPa}$ at $200^{\circ} \mathrm{C}$. The major components of this apparatus included positive liquid displacement pumps (P-1, P-2) (Thermal Separation Products, Riveira Beach, FL, USA) for solvent delivery $(46-460 \mathrm{~mL} / \mathrm{hr})$, one $300 \mathrm{~mL}$ highpressure extraction vessel ( E-1) (Autoclave Engineers, Erie, PA, USA) and two high-pressure columns (C-1, C-2) (300 mm X 12,7 mm I.D.) and separator flasks. The extraction vessel and the columns were supplied with heating jackets and temperature controllers and could be operated in series with three different arrangements. Heating tapes were used throughout the apparatus to maintain constant temperature in the entire equipment. In order to ensure constant and steady solvent delivery, pump heads were cooled circulating fluid through a chiller, CFT R134a (NESLAB Instruments, Newington, NH, USA). Flow rates and accumulated gas volumes passing through the apparatus were measured using a flow computer measuring device (FM-1) (EG\&G Instr. Flow Technology, Farmington Hills, Michigan, USA). Micrometering valves VM-1 (Autoclave Engineers, Erie-Pennsylvania, USA) were used for flow control throughout the apparatus. Heating tapes were also used around these valves to prevent freezing of solvents or solid solute precipitation following depressurization. Behind those valves three flasks were positioned in series to collect the solute after depressurization. The pressure in the extractor and columns was indicated by a digital transducer system (G1, G2, G3), Heise Series 901A RTS, acquired from Dresser Industries (Stratford, CT, USA) with $\pm 0.03 \mathrm{MPa}$ of precision. Extractor and column temperatures were controlled within $\pm 0.5^{\circ} \mathrm{C}$ of precision.

The compositions of the coffee extract fractions were determined by HPLC using a LC-10AD chromatograph (Shimadzu, Kyoto, Japan) and a $\mathrm{C}_{18}$ column ( $25 \mathrm{~cm} \times 4.6 \mathrm{~mm}, 5 \mu \mathrm{m}$, Supelco, USA). For the determination of the oil content in the extracts the mobile phase used was acetone/acetonitrile $(62: 38 \% \mathrm{v} / \mathrm{v})$ and the flow rate was $1.0 \mathrm{ml} / \mathrm{min}$ (González et a., 2001). A refractive index detector model RID 10A (Shimadzu, Kyoto, Japan) was used and the peaks were identified by comparison with pure standards (GC grade, $\geq 99 \%$, Sigma, St Louis, USA) and chromatographic profiles presented in the literature (González et a., 2001). The amounts of caffeine and chlorogenic acids in the extracts were determined using a detector SPD 10 AV (Shimadzu, Kyoto, Japan) operating at 280 and $313 \mathrm{~nm}$ respectively. Methanol $(50 \% \mathrm{v} / \mathrm{v})$ and $(40 \% \mathrm{v} / \mathrm{v})$ in aqueous sodium acetate $(0.5 \%)$ at a flow rate of 0.8 $\mathrm{ml} / \mathrm{min}$ was used as the mobile phase.

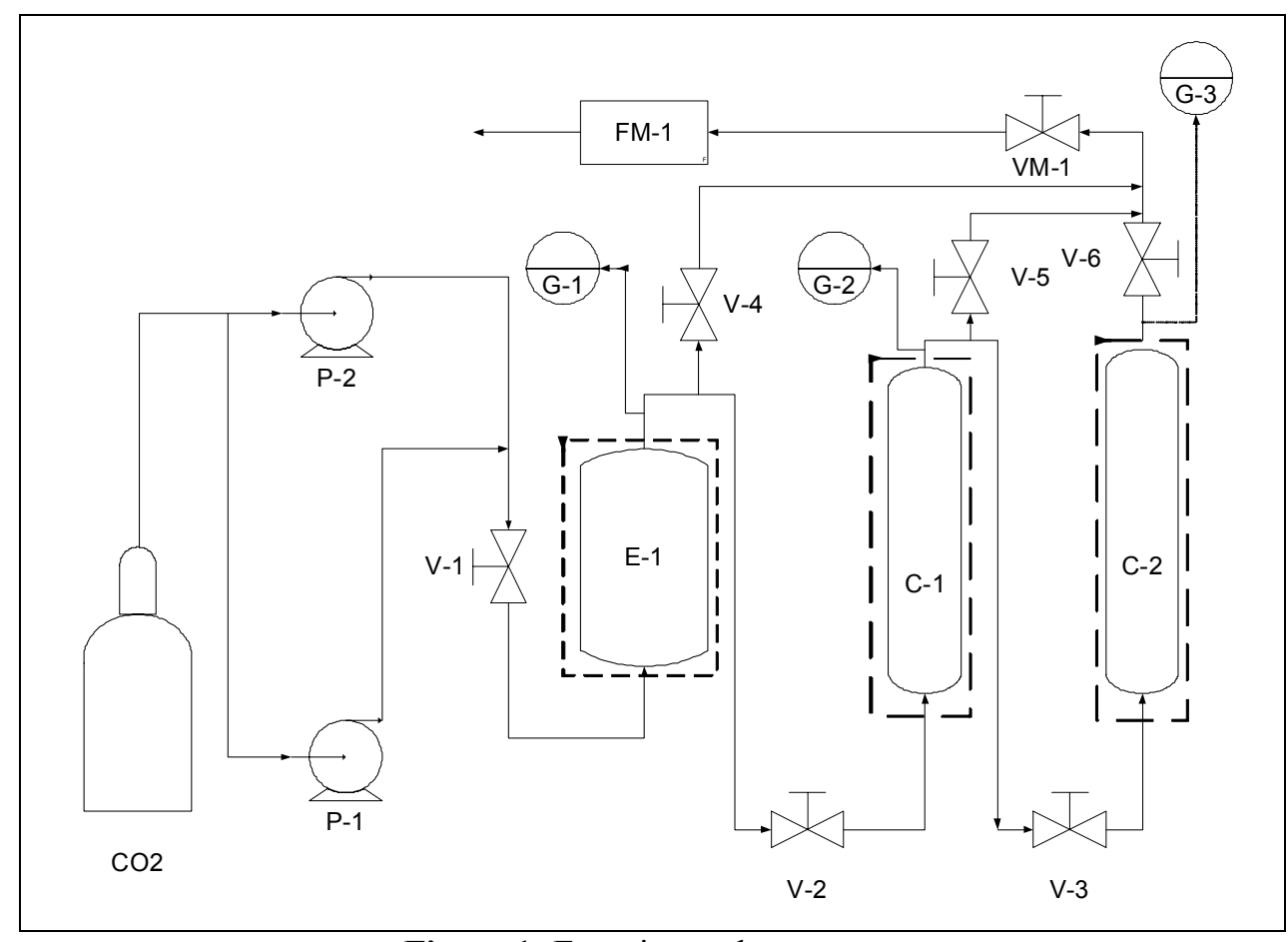

Figure 1: Experimental apparatus. 


\section{Experimental Procedures}

In order to explore the capacity of $\mathrm{CO}_{2}$ and $\mathrm{CO}_{2}$ aliphatic alcohol mixed solvents in the extraction of caffeine, coffee oil and chlorogenic acids from green coffee beans, experiments were carried out at $50^{\circ} \mathrm{C}$ and $60^{\circ} \mathrm{C}$ and pressures of $15.2,24.8$ and $35.2 \mathrm{MPa}$. Solvent mass flow rate was kept at $1.8 \mathrm{~g} / \mathrm{min}$. At this flow rate it can be assumed that equilibrium concentration for the solvent and solute is achieved (Filippi, 1982; Mohamed et al. 2000; Azevedo et al., 2003). Samples of $15 \mathrm{~g}$ of dried ground green coffee beans (average diameter of $0.725 \mathrm{~mm}$ ) were placed in the extractor. In a typical extraction experiment, solvent $\left(\mathrm{CO}_{2}\right.$ or $\mathrm{CO}_{2}$-alcohol mixed solvents) was delivered by the pumps as a liquid and slowly allowed into the extractor until the desired extraction pressure was reached. The extractor was heated until the extraction temperature and the micrometering valve positioned downstream of the extractor was slowly opened while maintaining the pressure constant in the extractor. The effluents of the extractor (supercritical fluid and the extracted components) were depressurized through the micrometering valve. The precipitated extract following depressurization was recovered in the separator flasks immersed in a cooling bath. Ethanol was placed in the last separator flask to assure complete recovery of precipitated coffee extract. In these particular experiments, fractions were collected at time intervals characterized by the passage through the extractor of 183 and $91.5 \mathrm{~g}$ of $\mathrm{CO}_{2}$ and, $\mathrm{CO}_{2}$-alcohol mixed solvents, respectively. The amount of solvent was determined through the gas flowmeter.

In order to estimate the oil extraction yield, the total oil content of the coffee beans was obtained by gravimetry after benzene extraction in a Sohxlet apparatus.

\section{RESULTS AND DISCUSSION}

\section{Coffee Oil}

The results obtained for the extractions carried out at both isothermal and isobaric conditions for supercritical $\mathrm{CO}_{2}, \mathrm{CO}_{2}$-isopropyl alcohol and $\mathrm{CO}_{2-}$ ethanol are shown in Figs. 2a, b and c, respectively. Each experimental point on the extraction curve represents the average value of two independent experiments with reproducibility within $\pm 6 \%$ for all extractions using supercritical $\mathrm{CO}_{2}, \mathrm{CO}_{2}$-isopropyl alcohol and $\mathrm{CO}_{2}$-ethanol. The data reveal that the amounts of coffee oil extracted using $\mathrm{CO}_{2}$-alcohol mixed solvents were higher than those obtained with supercritical $\mathrm{CO}_{2}$ at the same process conditions. The addition of co-solvents (5 wt.\%) in the formulation of the mixed solvent resulted in a reduction of $60 \%$ on the extraction time and the amount of solvent required to achieve an oil extraction yield of $70 \%$. The oil extraction yield was calculated comparing the extracted oil with the total oil content of the ground beans obtained by Sohxlet extraction. The results revealed that it is possible to obtain coffee oil extraction yields of $70 \%, 93 \%$ and $99 \%$ by weight when pure supercritical $\mathrm{CO}_{2}, \mathrm{CO}_{2}$-isopropyl alcohol and $\mathrm{CO}_{2}$-ethanol were used as solvents, respectively, at $60^{\circ} \mathrm{C}$ and $35,2 \mathrm{MPa}$.

The increase in the extraction yields obtained with the addition of alcohols as co-solvents can be attributed to the enhancement of solvent density and to modifications in both physical and chemical intermolecular interaction forces in the system (Ke et al., 1996). Experimental studies reported by Yonker and Smith (1988) and by Bulgarevich et al. (2002) showed that the addition of a co-solvent increases the local density around the solute molecule increasing the physical interaction, which are short range forces. Depending on the molecules characteristics it leads to the formation of specific interactions such as hydrogen bonding. The combination of an increase in density with the development of physical and chemical interactions has an important role on the formation of the solvation complex and consequently on the solubility. The improvement in the oil extraction process obtained with the addition of cosolvents is in agreement with extraction results of other oils from plant seeds as reported by Cocero and Calvo (1996), Azevedo and Mohamed (2001), among others.

At the same temperature and pressure higher yields were obtained when ethanol was used as a cosolvent instead of isopropyl alcohol. The mole fraction of ethanol and isopropyl alcohol in the mixtures were 0.048 and 0.038 , respectively, and at these compositions the mixed solvents presents approximately the same density as can be seen from the equilibrium data reported by Pöhler and Kiran (1997) and Zuniga-Moreno et al. (2002). The higher yields can therefore be attributed to the higher molecular ethanol content in the system. Steric effects can also negatively influence the efficiency of isopropyl alcohol as a co-solvent, due to the relative position of the hydroxyl group in the molecule (Ting et al., 1993).

The slope of the extraction curves in Fig. 2 gives the extraction rate, in $g$ extracted oil /g of solvent. At the beginning of the extraction, the process is phase equilibrium controlled and the diffusion of coffee oil from the seed surface to the supercritical fluid bulk phase is the unique mass transfer resistance considered here. The initial portion of the extraction curves in Fig. 2 describes the extraction rate due to the solubilization of surface available oil by the supercritical solvent (Hedrick et al., 1992). As 
expected, increasing pressure at constant temperature, increases solvent density and thus results in higher coffee oil extraction ratios.

The effect of pressure and temperature on the coffee oil extraction ratio at this solubility-controlled region is shown in Fig. 3. From these curves it can be seen that the extraction ratio of coffee oil varies from 0.2 to $3.5 \mathrm{~g} / \mathrm{kg}$ solvent as the $\mathrm{CO}_{2}$ density varies from 550 to $890 \mathrm{~kg} / \mathrm{m}^{3}$ (at $60^{\circ} \mathrm{C}$ ) for the system $\mathrm{CO}_{2}$-triacylgliceride. Based on the characteristics of the solute and solvent molecules, the only intermolecular interaction forces present in the system are of physical nature (dispersion and induction ones). These are short range forces and their intensity increase as the distance of the molecules decreases, leading to higher solvation complex formation (Morita and Kajimoto, 1990).

The influence of co-solvent on intermolecular interactions forces becomes evident when results of the effect of pressure on coffee oil extraction with $\mathrm{CO}_{2}$-alcohol mixtures are compared with those when pure $\mathrm{CO}_{2}$ was used. Densities of the mixture $90 / 10 \%$ $\mathrm{CO}_{2}$-ethanol at $50^{\circ} \mathrm{C}$ and pressures ranging from 10 to $57 \mathrm{MPa}$ are slightly higher than densities of only $\mathrm{CO}_{2}$ at the same temperature and pressures (Pohler and Kiran, 1997). So, the reduction of the extraction ratio for $\mathrm{CO}_{2}$ in comparison with $\mathrm{CO}_{2}$-isopropyl alcohol and $\mathrm{CO}_{2}$-ethanol mixtures, at the same pressure and temperature, as shown in Fig. 3, can be attributed to the presence of the induced dipole and the change on the dispersion interaction forces. The occurrence of specific interactions between the oxygen of the esterified carboxyl group of the triacylglyceride molecule and the hydroxyl group of the alcohol will also enhance the extraction rate. The co-solvent effect on $\mathrm{CO}_{2}$ mixtures diminishes as the pressure increases due to the saturation of the close region around the solute molecule and the selfassociation of co-solvent molecules (Bulgarevich et al., 2002; Santos et al., 2004).

Experimental data of oil extraction from seeds indicate the occurrence of a retrograde behavior, as reported by Friedrich et al. (1982) and Hadolin et al. (2001), and also by Reverchon et al. (2000) for the supercritical extraction of hiprose seed oil using $\mathrm{CO}_{2}$ as a solvent at temperatures of 40 and $70^{\circ} \mathrm{C}$. The small temperature interval investigated in this study with only two temperature levels suggests the existence of a retrograde behavior when using pure supercritical carbon dioxide and $\mathrm{CO}_{2}$-ethanol- mixed solvent with negligible influence on oil extraction rate.

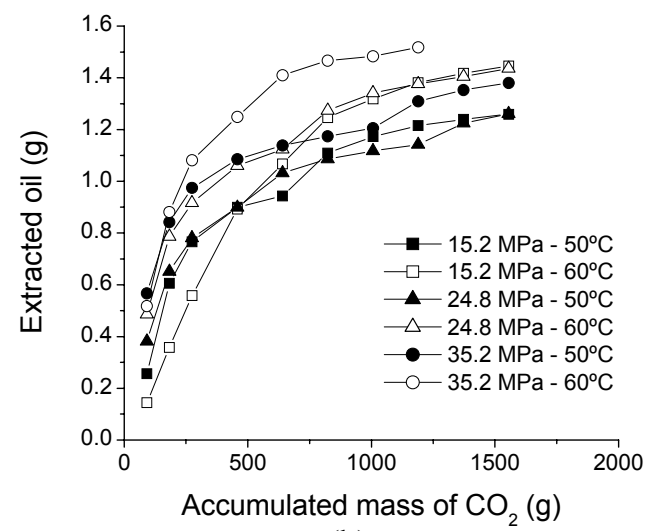

(b)

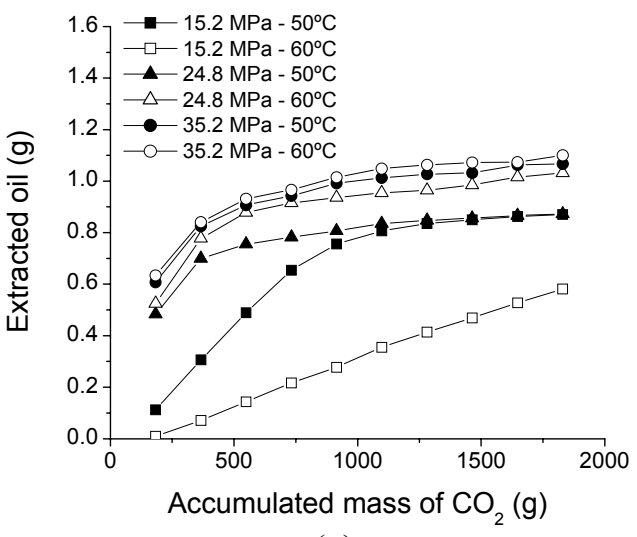

(a)

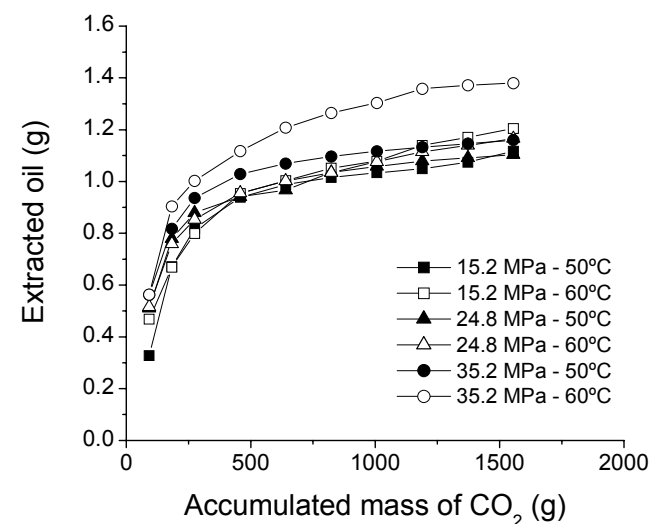

(c)

Figure 2: Coffee oil extraction curves. (a) pure $\mathrm{CO}_{2}$, (b) $\mathrm{CO}_{2}$ /ethanol and (c) $\mathrm{CO}_{2}$ isopropyl alcohol. 


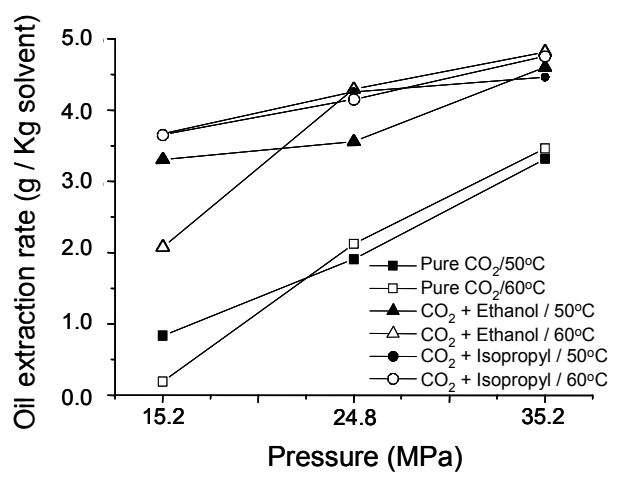

Figure 3: Coffee oil extraction rate as a function of pressure.

\section{Caffeine}

Figs. $4 \mathrm{a}, \mathrm{b}$ and $\mathrm{c}$ present the extraction curves obtained for caffeine. The yields, calculated as $\mathrm{g}$ caffeine / g of solvent, were $1.7 \%, 17 \%$ and $2 \%$ when supercritical $\mathrm{CO}_{2}, \mathrm{CO}_{2}$-ethanol and $\mathrm{CO}_{2}$ isopropyl alcohol were used as solvents, respectively. These yields are smaller than those reported by Peker et al. (1992) and Lack and Seidlitz (1993) for caffeine extraction from moistened coffee beans and using supercritical $\mathrm{CO}_{2}$ saturated with water. The low yield values can be attributed to the fact that caffeine molecules in coffee beans are complexed with chlorogenic acids (Horman and Viani, 1972), and the hydrogen bonds between caffeine and chlorogenic acid molecules have to be broken. The low co-solvent concentration could not be sufficient to break the complex and solvate the caffeine molecules. Kopcak et al. (2004) obtained yields of approximately one order of magnitude higher when the ethanol concentration in carbon dioxide was increased from 5 to $10 \%$ in mass for the extraction of caffeine from guaraná (Paullinia cupana) seeds.

The influence of the solute-matrix interactions was previously reported by Bjorklund et al. (1998) when extracting clevidipine from different matrices. As discussed above, $\mathrm{CO}_{2}$ has a high affinity to non polar species (Taylor, 1996), which is the case of triglyceride molecules, and the addition of a polar modifier can improve the extraction of polar species due to changes in intermolecular interactions. This explains the increase in caffeine extraction yields using ethanol and isopropyl alcohol as modifiers. The low caffeine yields obtained throughout this work can partially be attributed to additional resistance to mass transfer. Caffeine is found homogeneously distributed over the vegetable matrix and migrates by diffusion to the surface (Brunner, 1994).

The lower caffeine extraction yields observed when $\mathrm{CO}_{2}$-isopropyl alcohol was used as a solvent instead of ethanol can be attributed to the lower number of hydroxyl groups available to chemically interact (hydrogen bonding) with the alkaloid, and also to the loss of selectivity since chlorogenic acids were detected in the extracts only when isopropyl alcohol was used as a co-solvent, as discussed in the next section.

The effect of pressure and temperature on the initial caffeine extraction ratio is shown in Fig. 5. There was an increase in the amount of caffeine extraction with the increase in pressure when supercritical $\mathrm{CO}_{2}$ and supercritical $\mathrm{CO}_{2}$-ethanol were used as the solvents due to the increase in density and, thereby, an increase in extraction capacity. With supercritical $\mathrm{CO}_{2}$-isopropyl alcohol, the caffeine concentration in the extracts initially increased slightly with pressure and subsequently decreased although there was an overall increase of the accumulated mass extracted. Saldaña (1997) studied the extraction of caffeine from coffee beans with water saturated supercritical $\mathrm{CO}_{2}$ and observed that the total extraction of caffeine decreased with the increase in pressure (solvent density), despite an increase in the total mass extracted. This extraction behavior with pressure was also observed by $\mathrm{He}$ et al. (2003) and attributed to the lack of selectivity on the extraction of squalene from amaranth grains using supercritical $\mathrm{CO}_{2}$ as a solvent in a pressure range of 10 to $30 \mathrm{MPa}$ and temperatures ranging from 40 to $70^{\circ} \mathrm{C}$. The reported data show that the extraction ratio increased from 15 to $20 \mathrm{MPa}$ and decreased with pressures from 25 to $30 \mathrm{MPa}$. 


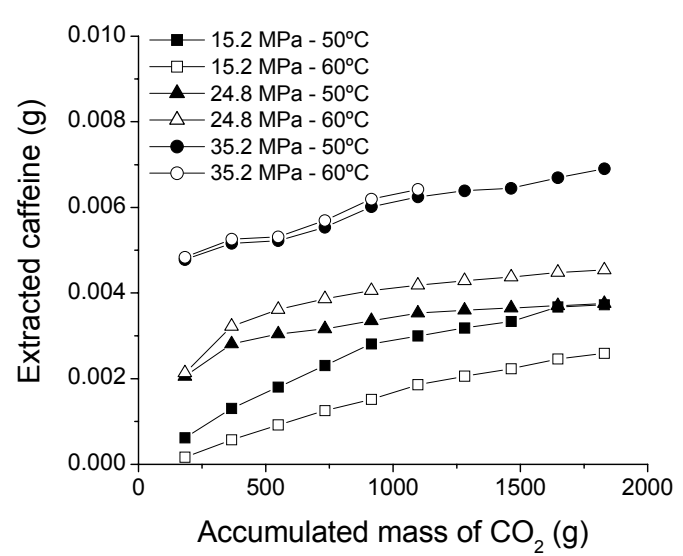

(a)

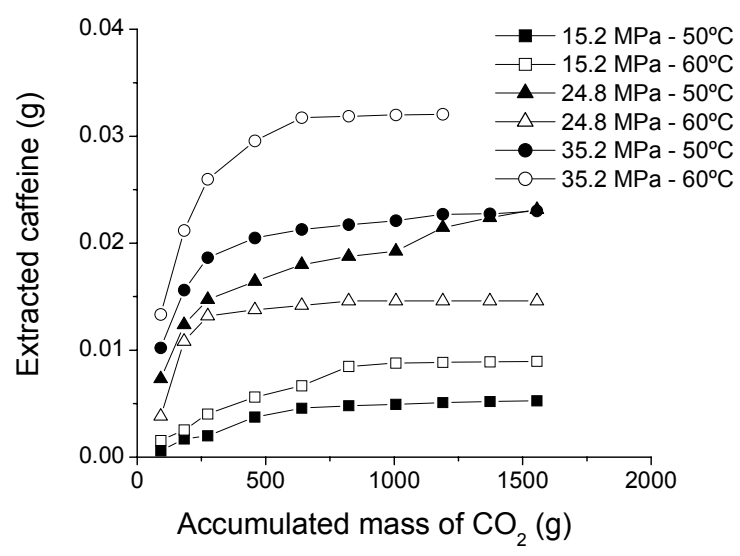

(b)

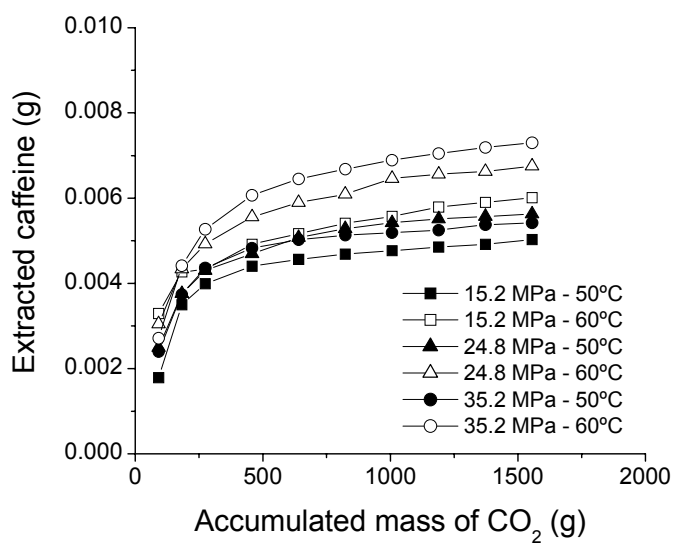

(c)

Figure 4: Caffeine extraction curves. (a) pure $\mathrm{CO}_{2}$, (b) $\mathrm{CO}_{2} /$ ethanol and (c) $\mathrm{CO}_{2} /$ isopropyl alcohol.

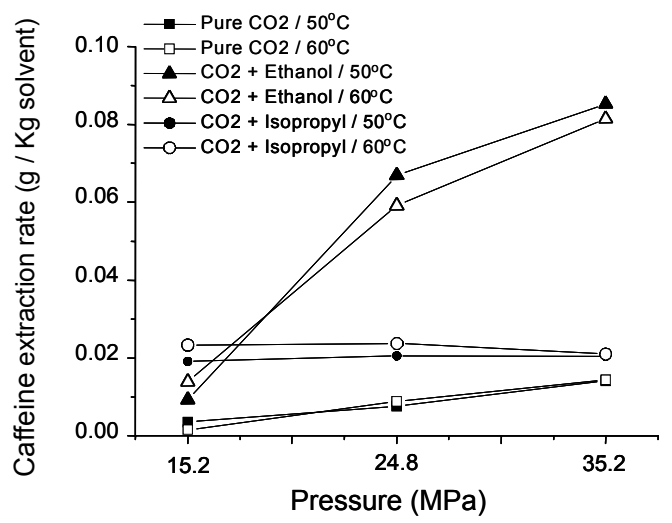

Figure 5: Caffeine extraction rate as a function of pressure.

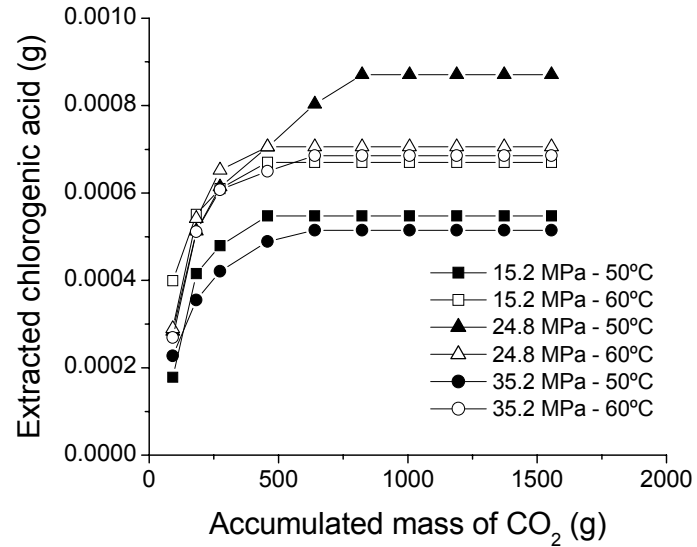

Figure 6: Chlorogenic acids extraction curves using $\mathrm{CO}_{2}$ /isopropyl alcohol as solvent. 


\section{Chlorogenic Acid}

Extraction experiments using pure $\mathrm{CO}_{2}$ and $\mathrm{CO}_{2}$ ethanol revealed that chlorogenic acids were only present as traces in the extracts. Chlorogenic acids were only detected in the extracts when the mixture $\mathrm{CO}_{2}$-isopropyl alcohol was used as a solvent (Fig. 6). The amount extracted is very small indicating a low solvent efficiency, although liquid isopropyl alcohol has been found a good solvent for conventional extraction of chlorogenic acids from coffee beans (Clifford, 1985). The low concentration of isopropyl alcohol used could be responsible for the inefficient extraction.

Specifically for chlorogenic acids the overall poor extraction efficiency can be attributed to the competition of these molecules with more polar components present in coffee beans (ex. sugars, phenols) as presumed by Azevedo (2005). Had the extraction process been continued for more time, it might have been that the chlorogenic acids would be extracted after the exhaustion of the other competitive components present in the coffee beans.

The effect of pressure on the extraction of chlorogenic acids was the same as observed for caffeine. These results are also in agreement with the assumption of a loss of solvent selectivity as pressure is increased (Brunner, 1983). The change on temperature did not produce a retrograde behavior in the extraction of chlorogenic acids.

\section{CONCLUSIONS}

An effective extraction of coffee green bean oil was obtained at $35.2 \mathrm{MPa}$, even when only supercritical $\mathrm{CO}_{2}$ was used as a solvent. The addition of ethanol and isopropyl alcohol as co-solvents resulted in an increase in the oil extraction, leading to yields of 93 and $99 \%$, respectively. The effect of co-solvents was associated with the modifications of intermolecular interaction forces and with the increase in solvent density. Increases in temperature showed a moderate retrograde behavior at $15.2 \mathrm{MPa}$ when $\mathrm{CO}_{2}$ and $\mathrm{CO}_{2}$-ethanol were used as solvent. Coffee oil has higher affinity with the solvents when compared to caffeine and chlorogenic acids. The low yields for caffeine and chlorogenic acids are probably due to the inability of the solvents to break down the caffeine-chlorogenic acid complex at low co-solvent concentration.

\section{ACKNOWLEDGEMENTS}

The authors thank Dulcinéia Pereira de Souza for the analysis of caffeine and chlorogenic acid and Uiram Kopcak for helping to prepare the manuscript. ABAA and PM thank Conselho Nacional de Desenvolvimento Científico e Tecnológico (CNPqBrazil) for research fellowships. This work received financial support from Fundação de Amparo a Pesquisa do Estado de São Paulo (FAPESP).

\section{REFERENCES}

Azevedo, A. B. A., Extração e recuperação dos princípios ativos do café utilizando fluidos supercríticos. PhD Thesis. State University of Campinas, Campinas-SP, Brazil (2005).

Azevedo, A. B. A. and Mohamed, R. S., Supercritical fluid extraction of cupuaçu fat from fermented seeds. Proceedings of the IV Brazilian Meeting on Supercritical Fluids, Salvador, BA, Brazil (2001).

Azevedo, A. B. A., Mohamed, R. S. and Kopcack, U. Supercritical fluid extraction and fractionation of cupuaçu fat from fermented seeds with supercritical solvents. Journal of Supercritical Fluids, 27, 223 (2003).

Bjorklund, E., Jareno, M., Mathiason, L., Jonsson, J.A. and Karlsson, L., Illustration of important mechanisms controlling mass transfer in supercritical fluid extraction. Analytica Chimica Acta, 368, 117 (1998).

Brunner, G., Selectivity of supercritical compounds and entrainers with respect to model substances. Fluid Phase Equilibria, 10, 289 (1983).

Brunner, G., Gas extraction an introduction to fundamentals of supercritical fluids and the applications to separation processes. New York, USA: Steinkopff Darmstadt Springer. (1994).

Bulgarevich, D. S., Sako, T., Sugeta, T., Otake, K., Takebayashi, Y., Kamizawa, C., Horikawa, Y. and Kato, M., The role of general and hydrogenbonding interactions in the solvation processes of organic compounds by supercritical $\mathrm{CO}_{2} / \mathrm{n}$ alcohol mixtures. Industrial and Engineering Chemistry Research, 41, 2074 (2002).

Clifford, M. N., Chlorogenic acids. In: Coffee: Chemistry (Edited by R.J. Clarke \& R. Macrae). Pp. 153-202. New York, USA:Elsevier Applied Science Publishers LTD. (1985). 
Cocero, M. J. and Calvo, L., Supercritical fluid extraction of sunflower seed oil with $\mathrm{CO}_{2}$-etanol mixtures. Journal of the American Oil Chemists' Society, 73, 1573 (1996).

Cordel, G. A., Biodiversity and drug discovery - a symbiotic relationship. Phitochemistry, 55, 463 (2000).

Debenedetti, P. G., Petsche, I.B. and Mohamed, R.S., Clustering in supercritical mixtures: theory, applications and simulations. Fluid Phase Equilibria, 52, 347 (1989).

Eggers, R., Supercritical fluid extraction (SFE) of oilseeds/lipids in natural products. In: Supercritical fluid technology in oil and lipid chemistry (Edited by J. W. King and G. R. List. Pp. 35-64. Champaign, Illinois, AOCS Press. (1996).

Filippi, R. P., $\mathrm{CO}_{2}$ as a solvent: applications to fats, oils and other materials. Chemical Industry, 19, 390 (1982).

Folstar, P., Lipids. In: Coffee: Chemistry (Edited by R.J. Clarke \& R. Macrae). Pp. 203-221. New York, USA:Elsevier Applied Science Publishers LTD. (1985).

Friedrich, J. P., List, G. R. and Heakin, A. J., Petroleum-free extraction of oil from soybeans with supercritical $\mathrm{CO}_{2}$. Journal of the American Oil Chemists' Society, 59, 288 (1982).

González, A. G., Pablos, F., Martín, M. J., LeónCamacho, M. and Valdenebro, M. S., HPLC analisys of tocopherol and triglycerides in coffee and their use as authentication parameters. Food Chemistry, 73, 93 (2001).

Hadolin, M., Skerget, M., Knez, Z. and Bauman, D., High pressure extraction of vitamin E-rich oil from Silybum marianum. Food Chemistry, 74, 355 (2001).

He, H. P., Corke, H. and Cai, J. G., Supercritical carbon dioxide extraction of oil and squalene from Amaranthus grain. Journal of the Agricultural and Food Chemistry, 51, 7921 (2003).

Hedrick, J. L., Mulcahey, L. J. and Taylor, L. T., Supercritical fluid extraction. Microchimica Acta, 108, 115 (1992).

Horman, I. and Viani, R., The nature and conformation of the caffeine-chlorogenate complex of coffee. Journal of Food Science, 37 , 925 (1972).

Ke, J., Mao, C., Zhong, M., Han, B. and Yan, H., Solubilities of salicylic acid in supercritical carbon dioxide with ethanol cosolvent. Journal of Supercritical Fluids, 9, 82 (1996).
Kim, S. W. and Johnston, K.P., Clustering in supercritical fluid mixtures. AIChE Journal, 33, 1603 (1987).

Kopcak, U., Azevedo, A.B.A. and Mohamed, R.S., Extraction of caffeine from guaraná (Paullinia cupana) seeds using supercritical mixed solvents. Proceedings of the $\mathrm{V}$ Brazilian Meeting on Supercritical Fluids, Florianópolis, SC, Brazil. (2004).

Lack, E. and Seidlitz, H., Decaffeination commercial scale of coffee and tea using supercritical $\mathrm{CO}_{2}$. In: Extraction of Natural Products using Nearcritical Solvents (Edited by M. B. King, Theodore Reginald Bott). Pp. 101-140. Birmingham, UK: Blackie Academic \& Professional. (1993).

Lima, D. R., Andrade, F. and Flores, G. B., Can coffee help fighting the drug problem? Preliminary results of a Brazilian youth drug study. Acta Pharmacologica Sinica, 21, 12, 1059 (2000).

Mazzafera, P., Soave, D., Zullo, M. A. T. and Guerreiro Filho, O., Oil content of green beans from some coffee species. Bragantia, 57, 45 (1998).

Mohamed, R. S., Extração e fracionamento de produtos de ocorrência natural com fluidos supercríticos. Ciência e Tecnologia dos Alimentos, 17, 344 (1997).

Mohamed, R.S., Saldaña, M. D. A., Socantaype, F. H. and Kieckbusch, T. G., Reduction in cholesterol content of butter oil using supercritical ethane extraction and adsorption on alumina. Journal of Supercritical Fluids, 16, 225 (2000).

Morita, A. and Kajimoto, O., Solute solvent interaction in nonpolar supercritical fluid - a clustering model and size distribution. Journal of Physical Chemistry, 94, 6420 (1990).

Okuno, S., Yoshinaga, M., Nakatani, M., Ishiguro, K., Yoshimoto, M., Morishita, T., Uehara, T. and Kawano, M., Extraction of antioxidants in sweetpotato waste powder with supercritical carbon dioxide. Food Science and Technology Research, 8, 154 (2002).

Peker, H., Srinivasan, M.P., Smith, J. M. and McCoy, B.J., Caffeine extraction rates from coffee beans with supercritical carbon dioxide. AIChE Journal, 38, 761-770 (1992).

Perrut, M., Supercritical fluid applications: Industrial developments and economic issues. Industrial and Engineering Chemistry Research, 39, 4531 (2000).

Pohler, H. and Kiran E., Volumetric properties of carbon dioxide plus ethanol at high 
pressures Journal of Chemical and Engineering Data, 42, 384 (1997).

Reverchon, E., Kaziunas, A. and Marrone, C., Supercritical $\mathrm{CO}_{2}$ extraction of hiprose seed oil: experiments and mathematical modeling. Chemical Engineering Science, 55, 2195 (2000).

Saldaña, M. D. A., Extração de cafeína, trigonelina e ácido clorogênico de café com $\mathrm{CO}_{2}$ supercrítico. MSc Thesis. State University of Campinas, Campinas-SP, Brazil (1997). http:/libdigi.unicamp.br/ document $/$ code $=$ vtls000120215

Saldaña, M. D. A, Zetzl, C. and Mohamed, R.S., Extraction of methylxanthines from guarana seeds, mate leaves, and cocoa beans using supercritical carbon dioxide and ethanol. Journal of Agricultural and Food Chemistry, 50, 4820 (2002a).

Saldaña, M. D. A, Mohamed, R. S. and Mazzafera, P., Extraction of cocoa butter from Brazilian cocoa beans using supercritical $\mathrm{CO}_{2}$ and ethane. Fluid Phase Equilibria, 194, 885 (2002b).

Santana, L. L. B., Cardos, L.A., Druzian, J. I., Souza, V. F., Costa, T. A. C., Nobrega, D. A., Hohlemwerger, S. V. A. and Velozo, E. S., Selectivity in the extraction of 2-quinolone alkaloids with supercritical CO2. Brazilian Journal of Chemical Engineering, 23, 525 (2006).

Santos, F. L. S., Tashima, A. K., Pessoa Filho, P. A. and Mohamed, R.S., Incorporação da abordagem química à equação de estado de Peng-Robinson para modelagem de compostos associativos. Proceedings of the XV Brazilian Congress of Chemical Engineering, Curitiba, PR, Brazil. (2004). Snyder, J. M., Friedrich J. P. and Christianson, D. D., Effect of moisture and particle size on the extractability of oils from seeds with supercritical $\mathrm{CO}_{2}$. Journal of the American Oil Chemists' Society, 61, 1851 (1984).

Subramanian, B., Rajewski, R. A. and Snavely, K., Pharmaceutical processing with supercritical carbon dioxide. Journal of Pharmacological Science, 86, 885 (1997).

Taylor. L., Supercritical fluid extraction. New York, USA: John Wiley \& Sons Inc. (1996).

Ting, S. S. T., Tomasko, D.L., Macnaughton, S. J. and Foster, N. R., Chemical-physical interpretation of co-solvents effects in supercritical fluids. Industrial and Engineering Chemistry Research, 32, 1482 (1993).

Yonker, C. R. and Smith, R. D., Solvatochromic behavior of binary supercritical fluids - the carbon dioxide 2-propanol system. Journal of Physical Chemistry, 92, 2374 (1988).

Zuniga-Moreno, A., Galicia-Luna, L. A., Horstmann, S., Ihmels, C. and Fischer, K., Compressed liquid densities and excess volumes for the binary systems carbon dioxide plus 1-propanol and carbon dioxide plus 2-propanol using a vibrating tube densimeter up to $25 \mathrm{MPa}$. Journal of Chemical and Engineering Data, 47, 1418 (2002). 